\title{
12 \\ Selected Legal Issues Related to Internet Use
}

\section{Gerald Quirchmayr}

Universität Wien, Institut für Angewandte Informatik und Informationssysteme, Liebigg. 4, A-1010 Wien, Austria, Phone ++431 40623 67, Fax ++431406 01 97, email: Gerald.Quirchmayr@univie.ac.at

\begin{abstract}
This paper aims at giving a survey of legal problems related to Internet, ranging from privacy and copyright issues which gain a new level of importance through WWW to liability problems and criminal law issues.
\end{abstract}

\section{Keywords}

Legal problems of Internet, Internet and privacy, liability, copyright, criminal law.

\section{MOTIVATION}

With the arrival of each new wave of technology, the legal framework finds itself lagging behind, but, with very few exceptions, the changes brought about by the new technology can be coped with by adapting the national legal framework. The Internet does however add a new quality, because it is the first technology which as part of its design is aimed at overcoming the concept of national borders. The applicability of laws and statutes is oriented territorially, which leads to a natural contradiction. Issues such as copyright, piracy, and liability have to be dealt with on an international level, therby 
offering a new challenge for international cooperation, both on a technical and on a legislative level.

\section{THE PROBLEM AREA}

The Internet is said to be changing every aspect of our work, the way in which we provide information, the way in which we search for it, the way in which we collaborate. In spite of basic communication technologies like text electronic mail having been around for many years now, the legal problems attached to this technology have not yet been solved completely. Authentication and electronic signature are still causing a wide variety of difficulties. In such an environment a technology like Internet which is pervasive and does not respect any national border is bound to lead to a large number of unanswered questions. Some of the arising problems however are not new, but become evident now due to the scale they reach on the Internet. Copyright and product piracy for example have always been a problem, the question of liability for information available on databases is nothing new, criminals making use of new technology have always been a nightmare for law enforcement agencies. The essential difference is the sheer scale of today's problems and the uncontrollability of the Internet. That is probably why some researchers have been arguing in favor of a so called "cyber law", regulating all aspects of information technology. Creating a separate legal framework for only one technology, no matter how revolutionary it is, is in sharp contrast to the legal tradition of most countries. Given the pervasiveness of Internet and the need for dealing with most of the related legal problems on an international level, this revolutionary approach to legislation might however be the optimal solution. 


\section{LEGAL ASPECTS OF INTERNET USE}

The intention of the following chapter is to give an overview of the most important problems from the user's point of view. The selection of problems reflects the personal view of the author and the areas dealt with below should be seen as representative and not as a complete list.

\subsection{Manipulation, Destruction, and Illegal Intrusion}

Illegal intrusion, manipulation of data, and destruction of systems is the traditional problem users have been confronted with since the first computer viruses and trojan horses have started to appear. With the rise of the Internet there is however a new dimension to the threat. Nationally occurring threats by viruses and other means of destruction can be countered by national laws. National laws do however have the limitation of being enforceable only within a certain territory, a concept which has been shown to be of limited value for dealing with attacks occurring on the Internet. Also if a certain criminal action is punishable under a national law and also if a court trial can be launched successfully, it might always be that the culprit is outside the respective jurisdiction; his actions might in an extreme case even be protected by the law of the nation he is operating from. International cooperation of police forces, as we see it today, definitely is not able to cope with this problem, mainly due to sometimes incompatible national legislation, a good example of which is the different attitude towards politicllay extremist views and pornographic material in the US end Europe. Taking up the fight against servers spreading extremist information by attacking these sites might be considered as reasonable act of self defense by one national law and as criminal offense by another, depending mostly on the moral and ethical values of the society. There are however situations which are covered in a more or less similar way by a majority of legal systems: installing viruses and trojan horses on ftp sites, breaking into corporate or governmental systems, as well as manipulating and destroying the content of information systems are punishable in most countries (for a good 
documentation of problems and technical countermaesures cf. [ACSAC '94] and [SEC '97],). The major problems arising with the Internet are those of prosecution and of the burden of proof. Getting hold of an offender in cyberspace certainly is not easy, securing the evidence of an illegal action is not trivial, and getting this evidence accepted by the judge is an additional headache. Law enforcement agencies and courts are confronted with a situation where traditional evidence is almost non existent and the only traces a crime leaves are its "electronic footprints". Procedures for dealing with such material in front of at courts have yet to be established, the experience of both prosecution and defense is in general very limited, clear guidelines for investigation forces are the exception.

\subsection{Violation of Intellectual Property Rights}

In a community which is used to software piracy not being treated as the crime it is and where the awareness of committing a crime by copying software or by passing on copies of software to friends and colleagues is at a very low level, if existent at all, the task of protecting intellectual property rights turns into a nightmare. There probably is no other environment than the Internet in which copyright regulations are so consequently ignored. This, among a variety of other problems has earned the Internet the reputation of being a "lawless place", a situation which is extremely embarrassing, especially due to the enormous size of the problem. With an incredible amount of multimedia data, sound, video, text and images being provided on a steadily increasing number of servers, copyright becomes more or less unenforceable. As intellectual property is one of the driving factors of our economy, this situation can easily lead to severe economic problems, a danger which is dramatically slowing down the process of building the information society (cf. [KnowRight '95]). With product piracy reaching a level of over $90 \%$ in some countries, the problem cannot be ignored any longer. The question however is what can be classified as piracy: only the exact copy of a product, a modified copy, copies of parts of a product? As long as it is a piracy of content, copyright laws 
may still be applicable, but when it comes to copying software, especially the so called "re-implementation", the copying of an algorithm, traditional copyright protection fails.

\subsection{Extremists, Fanatics, and Terrorists}

The possibility to easily spread propagandist material on the Internet is developing into a real danger for social peace. Newsgroups and even web sites are used by political and religious fanatics to deliberately target vulnerable groups of a society, clearly with the aim of promoting its collapse. As necessary as the freedom of speech and the freedom of opinion are for the functioning of a democracy, some limits must be introduced. It should not be allowed, as it is in some countries, to spread e.g. racist and fascist propaganda, especially when these activities are aimed at causing trouble in other parts of the world. Legal regulations and the basic values of freedom have to be brought into balance, because otherwise this unlimited freedom will turn against the society (cf [U. Maier-Rabler 95]) and lead to the collapse of its social and moral values or might in the long run produce an overreaction resulting in a stringent cencorship, abolishing all freedom on the Internet.

\subsection{Protection of Privacy}

In the interest of privacy and data protection, there must be limits to the content of data which is allowed to be spread on the Internet, especially in a medium which makes it possible to easily distribute information on a worldwide scale. Otherwise it will quickly become impossible to correct the effect of libel and slander, because once out on the Internet, the information becomes uncontrollable. The other border line which has been crossed by Internet users is the amount of personal data which is put on web sites, mainly about personalities of public interest and in many cases abusing freedom of information and freedom of speech, a behaviour which might in the not too far future lead to a limitation of these freedoms by legislators, as already attempted by porposals 
for communications dedency acts. Another, perhaps more promising way is the one pursued by the European Union [Directive 95/46/EC of the European Parliament and the Council of 24 October 1995], aiming at a harmonization of national laws. For a global economy, especially when it is based on a global technology, such an international standard is an enormous advantage, because by guaranteeing a commonly agreed standard level of protection it helps to ensure the free flow of information. For putting the technology to its full use, e.g. establishing electronic commerce and electronic shopping malls going beyond mere marketing, such a common legal framework covering the whole market is inevitable. For traditional businesses heavily relying on the exchange of information (e.g. mail order companies), the same holds true.

\subsection{Criminal Abuse}

Illegal intrusion and associated abuse are the forms of computer related crime our legal system has got used to dealing with, but the computer as tool for committing crime is a second field which legislators are not really aware of, though even very popular magazines as Time have published contributions with the focus on this problem ("The Mob gets wired"). That criminals do never hesitate to make use of a promising technology is an old wisdom of crime fighters, unfortunately renewed by recent developments on the Internet. For all sorts of criminals, from drug dealers coordinating shipments with electronic mail up to terrorists and abusers of children, the Internet has been a paradise far too long. Only fairly recently special investigation forces have started to go after the offenders. In most parts of the world the Internet however is still treated as a lawless zone, an area open for a wide variety of undesirable and frequently criminal activities. Sooner or later this situation will have to be ended, if the Internet shall serve as the backbone for international scientific cooperation which it was intended to be and as basis for the booming field of electronic commerce. As long as the situation continues to be as unsafe as it is right now and companies doing business on the Internet are prone to be attacked by hackers in the service of criminal organizations, the real potential of the technology, establishing a global virtual economy, will remain unused. 


\section{THE ROLE OF PROVIDERS AND SYSTEM ADMINISTRATORS}

Whereas the main interest of the user is to be protected against illegal intrusion, the violation of copyright and privacy and the major intention of the state should be to defended individuals and businesses against abuse and to inhibit the spreading of extremist, in some cases even terrorist, and indecent material, the situation of service providers and system administrators is completely different. The key question they have to ask themselves is what they can be held liable for. An attempt to categorize the liability leads to two separate classes of issues, the liability for the quality of the services being provided and the liability for abuse of their systems, mainly by authorized users. Negligence, which already is a difficult concept to deal with, has yet to be defined in this context.

\subsection{Reliability of the Services Provided}

According to several legal frameworks in a majority of countries the reliability of the services provided has to be at the state of the art, which means that the service has to be at a commonly accepted level of quality. For providers of Internet services this does not only mean having to meet the standard quality criteria for hardware and software, but, especially for access providers, having to guarantee a certain level of security, depending on the sensitivity of the information the user puts on the system. Whereas the maintenance of web sites will primarily demand to assure the availability and integrity of the information put on the system, communication services also have to take care of providing confidentiality and secrecy. Reality does however show that the encryption mechanisms provided are sometimes hopeless and that even the basics of data protection, such as regular backups and integrity checks are ignored by the vast majority of webmasters. Not being aware of their liability in case something goes wrong, providers and system administrators frequently fail to install proper security 
mechanisms and if they do, users are often left alone without the necessary support and training, so that they simply do not make use of the system in place or find ways to circumvent the procedures. Once more many lessons learned from software engineering, such as structured design, proper documentation, a solid training concept and a suitable maintenance strategy, seem to be ignored by a large part of a community embarking on a new technology.

\subsection{Liability for Abuse by Authorized Users}

System administrators and service providers being held liable for the services they provide is not new, but recently, mainly due to the global nature of the Internet, the idea has been introduced to additionally hold service providers liable for not controlling the behavior of their users. With users operating from outside the jurisdiction of a nation, service providers are the only ones a law enforcement agency can get hold of in case of the violation of national laws. That is why several governments are intending to introduce this form of liability, which from a scientific point of view looks more like a panic reaction intended to be able to at least put the blame on someone, if the abuser cannot be caught. A full liability of service providers must be rejected, because this would force them to police their users, surveilling every single step of their activities, a measure which would lead to the complete loss of privacy. A more reasonable concept is to hold service providers liable for negligently offering services to known criminals who can be expected to misbehave again. Negligence however has to be clearly defined; otherwise this idea will cause an unacceptable amount of insecurity among service providers, thereby undermining this in the near future extremely important sector of our economies. 


\section{THE NEED FOR AN INTERNATIONAL LEGAL FRAMEWORK}

However excellent and well designed the legal framework of a nation will be, it cannot cope with the problems created by the Internet which is in its design a global concept. That is why in the long run only an international legal framework will provide the safe environment which is the basis for businesses to operate in.

In its data protection guidelines the European Union has shown a very promising approach towards the harmonization of laws in the field of information technology [Directive 95/46/EC of the European Parliament and the Council of 24 October 1995]. This sort of harmonization of national laws, rather than "one law covering the world" must be the first phase, considering the size of the problem a rather modest step, if acceptance by national governments and legislative bodies is to be reached. Only in a later step can a common legal framework be put into place. The difficulties in putting together such guidelines still are enormous, taking into account that the European Union has a long tradition of successfully establishing common legal frameworks compared to the rest of the world. Given the emergence of similar blocks, like NAFTA and MERCOSUR, the EU's approach might soon be followed and once the major players in the field agree on a common standard, they should be able to convince the rest to accept the standards they put in place.

On a truly global scale organizations like WIPO are also contributing to paving the road to common legal frameworks. As the activities of the United Nations Crime Prevention and Criminal Justice Division and its partner institutions show, the law enforcement community has also been active on the Internet for quite a while (see [UNCJIN Newsletters], http://www.ifs.univie.ac.at/ uncjin, http://www.unojust.org), encouraging other international, regional, and national agencies to follow their example (for an example of teaching activities cf. [A.C. Bouloukos 95]). Some national agencies have 
put a lot of effort into making use of the Internet right from the beginning, the best representative being the FBI (http://www.fbi.gov).

\section{CONCLUSION}

The road towards a common legal framework and towards jointly organizing the fight against criminals and abusers of loopholes in national legal systems might still be long, but the major step, the creation of awareness of the size of the problem is well under way. Economic pressure and the efforts of international organizations will also contribute to establishing the environment necessary for creating a global legal framework, which in a first step will probably be a mixture of guidelines in the style of the European Union and typical UN-style treaties. It has widely been realized that a technology as powerful as the Internet simply is to valuable for not embedding it in a safe legal framework ensuring that businesses can securely make use of it.

\section{REFERENCES}

[ACSAC '94] Proceedings of Tenth Computer Security Applications Conference (ACSAC '94), IEEE Computer Society Press, ISBN 0-8186-6795-8.

[A.C. Bouloukos 95] A.C. Bouloukos, D.C. Benamati, G.R: Newman, Teaching Information Literacy in Criminal Justice: Observations from the University of Albany, Journal of Criminal Justice Education, vol. 6/2, 1995.

[Directive 95/46/EC of the European Parliament and the Council of 24 October 1995] Directive 95/46/EC of the European Parliament and the Council of 24 October 1995 on the protection of individuals with regard to the processing of personal data and on the free movement of such data. Official Journal of the European Communities, ISSN 0378-6978, L 281, Volume 38, 23 November 1995.

[KnowRight '95] K. Brunnstein et al. (eds.), Proceedings of KnowRight 95, Oldenbourg, 1995, ISBN 385403-082-7.

[U. Maier-Rabler 95] U. Maier-Rabler et al., Netz ohne Eigenschaften, Salzburg, April 1995.

[SEC '97] S.K. Katsikas and D. Gritzalis (eds.), Proceedings of IFIP Conference Information Systems Security, Facing the information society of the 21st century, Chapman \& Hall 1997, ISBN 0412-78120-4.

[UNCJIN Newsletters] UNCJIN Newsletters, published by UN CPCJD (http://www.ifs.univie.ac.at/ uncjin/newsletter). 